\title{
COLOR PERCEPTION OF THE OBSERVER WITH THE MANIFESTATION OF THE CHROMATIC EFFECT OF CRISPENING
}

\author{
Krunoslav HAJDEK, Petra BRADIĆ, Martina HAJDEK, Mile MATIJEVIĆ
}

\begin{abstract}
This research presents the results of the appearance of chromatic effect of crispening on a designer solution in which the primary stimuli are made in the purple color with the values of $55 \%$ RTV and $65 \%$ RTV and backgrounds are made in the green-blue color, and their variations are designed in the values of $25 \%$ RTV, $50 \%$ RTV, $75 \%$ RTV and $100 \%$ RTV that are placed around the primary stimuli. The test subjects $(n=10)$ that took part in the research had the task to equalize the test primary stimuli with the referential stimuli on a computer screen with the help of the technique of simultaneous binocular harmonization. The strength of the crispening effect was defined and shown in the CIEDE00 system. The conclusion of the conducted tests indicates that the intensity of crispening was stronger on the test primary stimuli $65 \%$ RTV, where the differences in the perception of color were more significant.
\end{abstract}

Keywords: color; crispening; perception; vision adaptation; visual psychophysics

\section{INTRODUCTION}

Simultaneous contrast is one of the oldest illusions for perception. Simultaneous contrast is a psychophysical visual effect that causes a shift in the manifestation of the color of a stimulus. It is caused by a change in the background color (Fig. 1). Simultaneous contrast is the effect that shows that the representation of one part of light depends not only on the light but also on the context in which the light is presented $[1,2]$. The effect of simultaneous contrast is a subjective psychological experience, which is proved by the fact that the same physical stimulation (the same dominant wavelength) in different people causes different color experiences. Studying the phenomenon of simultaneous contrast has a long history [3]. It is one of the most studied phenomena ever since Aristotle's time [4]. Despite more than a century of intense research and study of simultaneous contrast, it is still a confusing and poorly understood phenomenon [5].

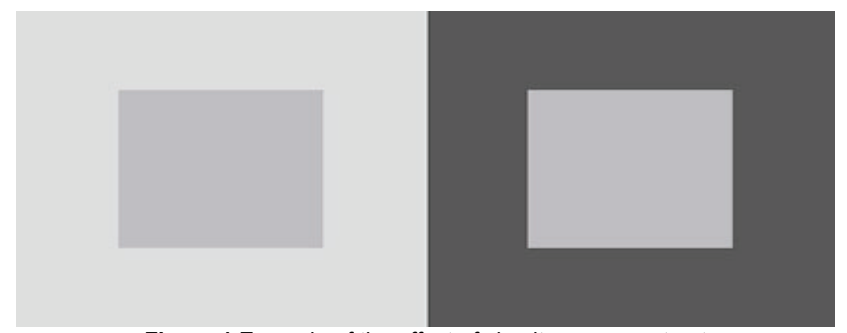

Figure 1 Example of the effect of simultaneous contrast

There are two explanations for this effect. One explanation stems from Herning's idea of processes in the optical system [6, 7], whereas the other stems from Helmholtz [8], who claims that the effect is a result of erroneous illumination.

As we very rarely see a particular color, isolated simultaneous contrast affects our sensation of the color we see. Put differently, a background which is light causes the enhancement of the characteristics of a particular stimulus so that it may appear darker, i.e. a dark background affects the perception on its surface so that the observed stimulus appears lighter on it. Many studies include color and its lightness, which are mostly described by the scientists Beck [9] and Wyszecki [10].

The main parameter in color dynamics is the contrast that also has a great impact on color perception. The contrast describes the influence of one color on the perception of colors in adjacent areas [11]. Contrast is the difference of luminance between the surfaces of different areas and/or elements on the surface [12]. When placing a brighter color as the background, the color appears darker; while when placing a darker color as the background, the color appears brighter.

Apart from the aforementioned psychophysical visual effect of achromatic simultaneous contrast which is also called achromatic induction, there is also chromatic induction which is based on the difference between the chromatic pairs of colors.

The psychophysical visual effect that seemingly increases the intensity of the perception of color between the two stimuli of color that are being compared is called crispening (Fig. 2). The background itself, in that case, must be very similar to the perception of the color of the stimuli [13].

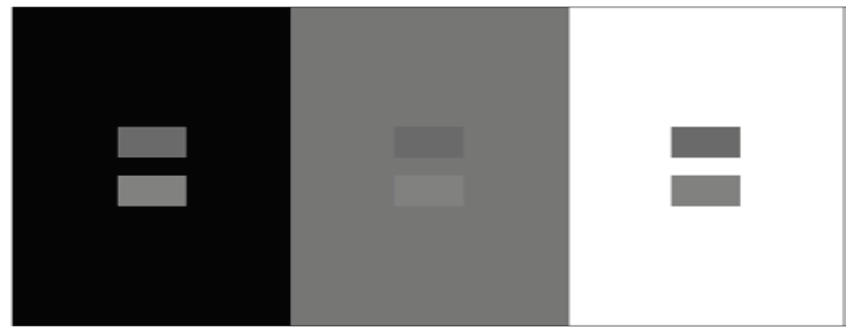

Figure 2 Example of the crispening effect

The effect of crispening was first discovered and named by Takasaki in his papers $[14,15]$. Semmerloth [16] follows his research, and recently, the scientist Whittle is significantly involved in the research of the crispening effect 
[17]. Hajdek et al. already explored in what way the crispening effect [18] and the simultaneous contrast effect $[19,20]$ with a change in background lightness affect the perception of the respondents.

In each research of the crispening effect, it is always necessary to determine to what extent the variations in the lightness or color of the background affect the shift in the cognizance of the viewer, and to establish the difference that will be present on the same model that causes the appearance of the background effect and that is presented in another media. Accordingly, it was sought, by using particular formulas, to establish in advance the possible intensity of the crispening effect in relation to the switch in the lightness/color of the background [21, 22].

In this article, what is presented are the results of the research of the appearance of the chromatic crispening effect on a designer solution where the inner squares (primary stimuli) are made in the purple color with the values $55 \%$ RTV and 65\% RTV, and the backgrounds (secondary stimuli) are made in the green-blue color and their variations are designed in the values of $25 \% \mathrm{RTV}, 50 \% \mathrm{RTV}, 75 \% \mathrm{RTV}$ and $100 \%$ RTV which encircle the inner squares. The selected RTV values of primary stimuli (55\% RTV and $65 \%$ RTV) and secondary stimuli (25\% RTV, 50\% RTV, 75\% RTV and $100 \%$ RTV) were used to cover the entire area of RTV color coverage from $0 \%-100 \%$ RTV in increments of $25 \%$ RTV. Backgrounds are divided into four areas $0-25 \%$ RTV, 25\%-50\% RTV, 50\%-75\% RTV and 75\%-100\% RTV. Primary stimuli of $55 \%$ RTV and $65 \%$ RTV were used as mean values, but the value of $50 \%$ RTV for primary stimuli was avoided because that value would cause an effect of assimilation at the same value of background $[19,20]$.

\section{EXPERIMENTAL PART}

This research is a continuation of the research conducted by the same authors [23]. In this part of the work, samples due to which the manifestation of the crispening effect appears were designed. The chromatic test samples were designed in a next manner: as a secondary stimulus, a square was colored in the green-blue color; and for the primary stimulus, the purple color was used. For the background, four variations were used; the initial secondary stimuli had the value of $25 \%$ RTV, and every following background was increased by $25 \%$ RTV. Within this geometrical shape, there are two same, but smaller geometrical shapes which represent the primary stimuli, and they are painted in the purple color that has the value of 55\% RTV for the left rectangle and 65\% RTV for the right rectangle (Figs. 3-6). The mentioned samples are seen as referential, and below them, there were samples with the background of a particular value, and on them were empty fields (white) of the primary stimuli, where the subjects had the task of choosing the harmonized values of the primary stimuli so that the test primary stimuli be, as they perceive them, the same/similar as possible to the referential primary stimuli.

Test samples were designed in the Indesign CC program, and the referential primary stimuli had the following Lab values: square of $55 \% \mathrm{RTV} ; L=72,00, a=41,00$ and $b=$
$-6,00$, and the values of the referential primary stimuli of $65 \%$ RTV were $L=67,00, a=49,00$ and $b=-7,00$. The test subjects in the experiment used the technique of simultaneous binocular harmonization $[24,25]$ (original and reproduction are in visual field at the same time), and they were given the instructions to try to harmonize (equalization of the referential and test primary stimuli in order so they are perceived the same or equally) in the Indesign CC program the empty fields so that they are the same/similar to the value of the field of the referential primary stimuli that are situated right above the test sample, and the secondary stimuli were in the corresponding values of all four RTV $(25 \%$ RTV$100 \%$ RTV), on the referential sample and the test sample respectively.

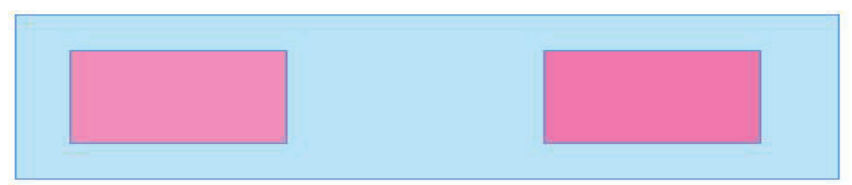

Figure 3 Used sample with the background of 25\% RTV and the inner squares of $55 \%$ RTV $(\mathrm{L})$ and $65 \%$ RTV (R)

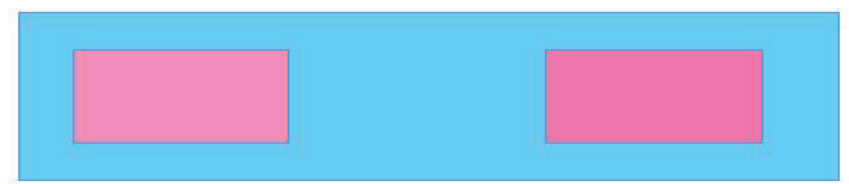

Figure 4 Used sample with the background of $50 \%$ RTV and the inner squares of $55 \%$ RTV (L) and $65 \%$ RTV (R)
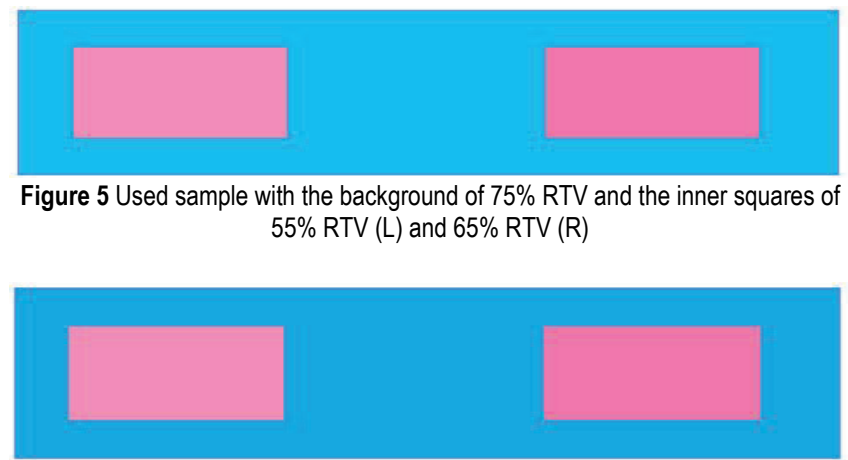

Figure 6 Used sample with the background of 100\% RTV and the inner squares of $55 \%$ RTV (L) and $65 \%$ RTV (R)

The lack of the Indesign CC program is that the mentioned program allows only the use of whole numbers without decimal points.

The samples were evaluated on a Lenovo G580 portable computer that had a LED-backlit HD Vibrant View display, diagonal of the screen of $15.6 "$ and a resolution of $1366 \times 768$. The conditions in which the experiment was carried out were in conformity with the ISO 3664:2009 guidelines (distance from the screen of $60 \mathrm{~cm}$, viewing angle of $10^{\circ}$ and D50 lighting), and the subjects had unlimited time for their experimental evaluation.

Ten subjects of both sexes with no previous experience in the research of this type evaluated the samples. Every test subject who was involved in the experiment had to pass the 
Ishihara test for defective color vision which confirmed that every subject was $100 \%$ successful on the test. [26].

The research results are presented with the $\Delta E_{00}$ formula

$$
\begin{aligned}
\Delta E_{00}= & {\left[\left(\frac{\Delta L^{\prime}}{k_{L} S_{L}}\right)^{2}+\left(\frac{\Delta C_{a b}^{\prime}}{k_{C} S_{C}}\right)^{2}+\left(\frac{\Delta H_{a b}^{\prime}}{k_{H} S_{H}}\right)^{2}+\right.} \\
& \left.+R_{T}\left(\frac{\Delta C_{a b}^{\prime}}{k_{C} S_{C}}\right)\left(\frac{\Delta H_{a b}^{\prime}}{k_{H} S_{H}}\right)\right]^{0.5}
\end{aligned}
$$

Where $S_{L}$ stands for lightness compensation, $S_{C}$ for chroma compensation, $S_{H}$ for hue compensation and $R_{T}$ for hue rotation. The $k_{L}, k_{C}$ and $k_{H}$ factors are the unity and weighting factors that depend on the material that they are being measured on (graphic arts of textiles).

$$
\begin{aligned}
& \Delta L=L_{b}^{\prime}-L_{s}^{\prime} \\
& \Delta C_{a b}^{\prime}=C_{a b, b}^{\prime}-C_{a b, s}^{\prime} \\
& \Delta H^{\prime}{ }_{a b}=\left[2\left(C_{a b, b}^{\prime} C_{a b, s}^{\prime}\right)^{0.5} \sin \left(\frac{\Delta h_{a b}^{\prime}}{2}\right)\right]
\end{aligned}
$$

\section{RESEARCH RESULTS WITH DISCUSSION}

In this section, the results of the research present how big the difference between the referential and test samples is by using the $\Delta E_{00}$ values. After subjects made the harmonization, with the use of the color picker tool, Lab

\begin{tabular}{|c|c|c|c|c|c|c|c|c|c|c|c|c|c|c|c|c|}
\hline \multirow[b]{2}{*}{ Subjects } & \multicolumn{4}{|c|}{$25 \%$ RTV } & \multicolumn{4}{|c|}{$50 \%$ RTV } & \multicolumn{4}{|c|}{$75 \%$ RTV } & \multicolumn{4}{|c|}{$100 \%$ RTV } \\
\hline & $L$ & $a$ & $b$ & $\Delta E$ & $L$ & $a$ & $b$ & $\Delta E$ & $L$ & $a$ & $b$ & $\Delta E$ & $L$ & $a$ & $b$ & $\Delta E$ \\
\hline 1 & 77 & 32 & -6 & 5.04 & 75 & 35 & -6 & 2.90 & 75 & 35 & -6 & 3.16 & 78 & 31 & -5 & 5.82 \\
\hline 2 & 69 & 46 & -7 & 2.88 & 69 & 46 & -7 & 2.88 & 70 & 44 & -6 & 1.84 & 69 & 46 & -7 & 2.88 \\
\hline 3 & 71 & 42 & -6 & 0.83 & 71 & 43 & -6 & 1.03 & 71 & 42 & -6 & 0.83 & 72 & 41 & -6 & 0.00 \\
\hline 4 & 69 & 45 & -6 & 2.68 & 69 & 46 & -7 & 2.87 & 69 & 45 & -6 & 2.68 & 70 & 44 & -6 & 1.84 \\
\hline 5 & 70 & 44 & -6 & 1.85 & 70 & 44 & -6 & 1.85 & 68 & 48 & -7 & 3.88 & 69 & 47 & -7 & 3.07 \\
\hline 6 & 73 & 39 & -6 & 1.04 & 71 & 43 & -6 & 1.03 & 72 & 41 & -6 & 0.00 & 70 & 44 & -5 & 1.95 \\
\hline 7 & 71 & 42 & -6 & 0.84 & 71 & 42 & -6 & 0.84 & 71 & 42 & -6 & 0.84 & 73 & 40 & -6 & 0.83 \\
\hline 8 & 69 & 46 & -7 & 2.88 & 68 & 48 & -7 & 3.88 & 69 & 45 & -6 & 2.68 & 69 & 46 & -7 & 2.87 \\
\hline 9 & 7 & 44 & -6 & 1.85 & 70 & 44 & -6 & 1.85 & 71 & 43 & -6 & 1.03 & 72 & 41 & -6 & 0.00 \\
\hline 10 & 70 & 44 & -6 & 1.85 & 72 & 41 & -6 & 0.00 & 72 & 41 & -6 & 0.00 & 74 & 38 & -6 & 1.85 \\
\hline
\end{tabular}
values were measured on all test samples in the Indesign CC program, and the size of the difference in color between the referential and the test samples was presented with the $\Delta E_{00}$ formula.
Tab. 1 presents every Lab value individually, for every test subject who harmonized the test primary stimuli compared to the referential primary stimuli with the value of $55 \%$ RTV on every background variation $(25 \%$ RTV, $50 \%$ RTV, 75\% RTV, and 100\% RTV).

\begin{tabular}{|c|c|c|c|c|c|c|c|c|c|c|c|c|c|c|c|c|}
\hline & \multicolumn{4}{|c|}{$25 \%$ RTV } & \multicolumn{4}{|c|}{$50 \%$ RTV } & \multicolumn{4}{|c|}{$75 \%$ RTV } & \multicolumn{4}{|c|}{$100 \%$ RTV } \\
\hline Subjects & $L$ & $a$ & $b$ & $\Delta E$ & $L$ & $a$ & $b$ & $\Delta E$ & $L$ & $a$ & $b$ & $\Delta E$ & $L$ & $a$ & $b$ & $\Delta E$ \\
\hline 1 & 66 & 51 & -7 & 1.02 & 68 & 48 & -7 & 0.85 & 63 & 56 & -7 & 3.90 & 72 & 41 & -6 & 4.71 \\
\hline 2 & 64 & 55 & -7 & 3.04 & 65 & 54 & -7 & 2.22 & 65 & 54 & -7 & 2.22 & 64 & 55 & -7 & 3.04 \\
\hline 3 & 64 & 56 & -7 & 3.22 & 64 & 55 & -7 & 3.04 & 64 & 55 & -7 & 3.04 & 66 & 51 & -6 & 1.02 \\
\hline 4 & 64 & 55 & -7 & 3.05 & 64 & 56 & -7 & 3.23 & 65 & 53 & -7 & 2.03 & 66 & 52 & -7 & 1.23 \\
\hline 5 & 65 & 54 & -7 & 2.22 & 67 & 49 & -7 & 0.00 & 63 & 57 & -7 & 4.06 & 66 & 51 & -7 & 1.02 \\
\hline 6 & 69 & 46 & -7 & 1.85 & 69 & 46 & -7 & 1.85 & 67 & 49 & -7 & 0.00 & 68 & 48 & -7 & 0.86 \\
\hline 7 & 69 & 45 & -6 & 2.07 & 67 & 50 & -7 & 0.31 & 69 & 46 & -7 & 1.85 & 68 & 48 & -7 & 0.86 \\
\hline 8 & 67 & 49 & -7 & 0.00 & 65 & 53 & -7 & 2.03 & 65 & 53 & -7 & 2.03 & 64 & 55 & -7 & 3.05 \\
\hline 9 & 65 & 54 & -7 & 2.22 & 64 & 56 & -7 & 3.23 & 6 & 55 & -7 & 3.05 & 63 & 56 & -7 & 3.90 \\
\hline 10 & 68 & 48 & -7 & 0.86 & 68 & 48 & -7 & 0.86 & 69 & 47 & -7 & 1.71 & 67 & 49 & -7 & 0.00 \\
\hline
\end{tabular}

It can also be seen from Tab. 1 how large the value of the $\Delta E_{00}$ difference between both samples for every test subject individually is.

Table 2 Display of the associated Lab values of the primary stimuli of $65 \%$ RTV for the test samples on all four background variations

Tab. 2 presents every Lab value individually, for every test subject who harmonized the test primary stimuli compared to the referential primary stimuli with the value of $65 \%$ RTV on every background variation.

It can also be seen from Tab. 2 how large the value of the $\Delta \mathrm{E} 00$ difference between both samples for every test subject individually is.

In the next part of the article, Figs. 7-10 present the measured difference of the $\Delta E_{00}$ value for every test subject on the primary stimuli of 55\% RTV, and the difference is shown for every secondary stimulus individually.

In Fig. 7, subjects harmonized the primary stimuli of $55 \% \mathrm{RTV}$, where the background is of $25 \% \mathrm{RTV}$, and it shows that the biggest difference belonged to subject 1 , while on the other hand, the smallest difference belonged to subjects 3 and 7, where the difference basically does not exist due to the fact that subjects harmonized the values of both stimuli very close to each other. 


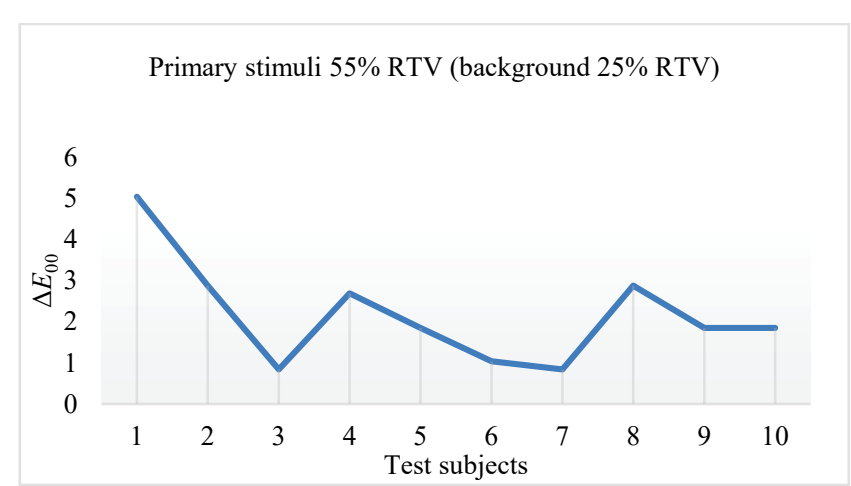

Figure 7 Display of the $\Delta E_{00}$ difference for every subject for the primary stimuli of $25 \%$ RTV on the secondary stimuli of $25 \%$ RTV

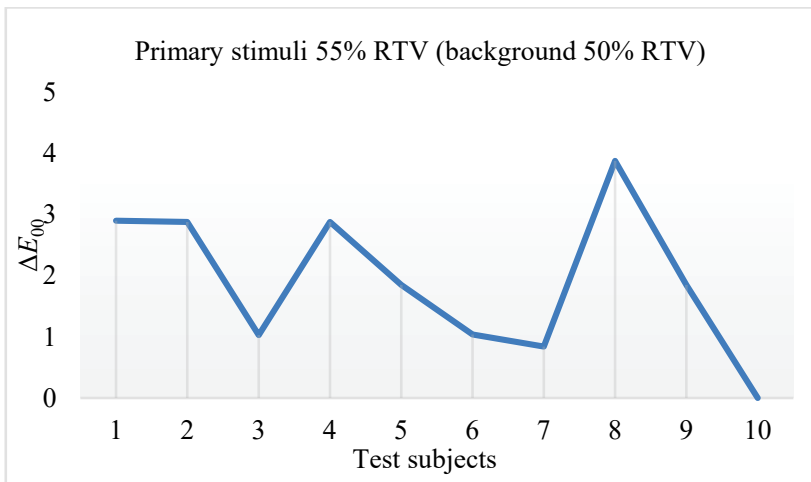

Figure 8 Display of the $\Delta E_{00}$ difference for every subject for the primary stimuli of $55 \%$ RTV on the secondary stimuli of $50 \%$ RTV

Fig. 8 presents the results of harmonization on the primary stimuli of $55 \%$ RTV with the background of $50 \%$ RTV, and it shows that the biggest difference belonged to subject 8 , while on the other hand, the smallest difference belonged to subject 10; in fact, there is no difference due to the fact that the subject harmonized the values of the test stimuli equivalently to the values of the original pattern.

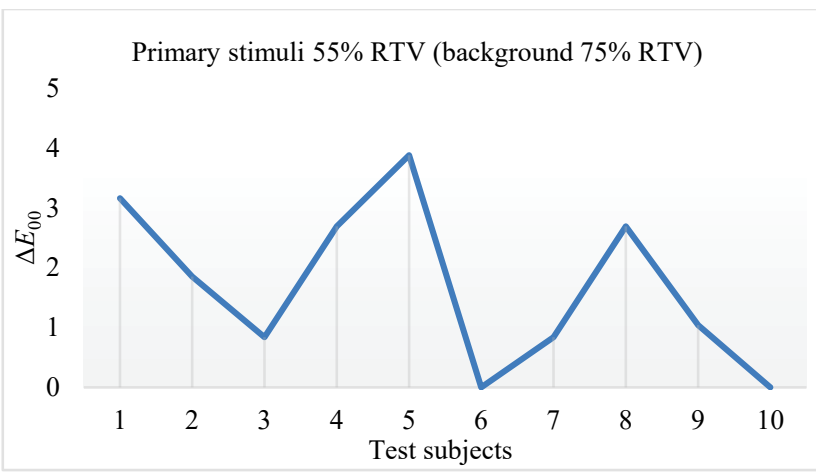

Figure 9 Display of the $\Delta E_{00}$ difference for every subject for the primary stimuli of $55 \%$ RTV on the secondary stimuli of $75 \%$ RTV

Fig. 9 shows the harmonization of the primary stimuli of $55 \%$ RTV on the background of $75 \%$ RTV, and it shows that the biggest difference belonged to subject 5 , while on the other hand, the smallest difference belonged to subjects 6 and 10; in fact, there are no differences.

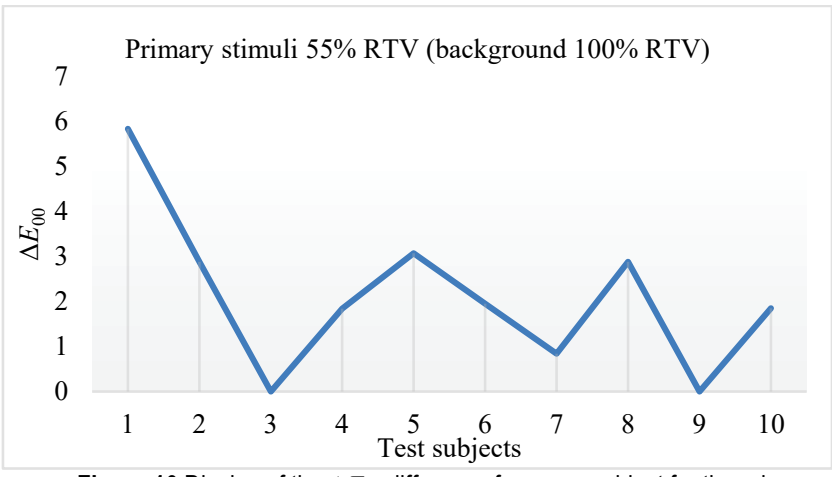

Figure 10 Display of the $\Delta E_{00}$ difference for every subject for the primary stimuli of $55 \%$ RTV on the secondary stimuli of $100 \%$ RTV

Fig. 10 presents the primary stimuli of $55 \%$ RTV on the background of $100 \% \mathrm{RTV}$, and it shows that the biggest difference belonged to subject 1 , while on the other hand, the smallest difference belonged to subjects 3 and 9 , as they harmonized test primary stimuli equivalently to the values of the original (referential) stimuli.

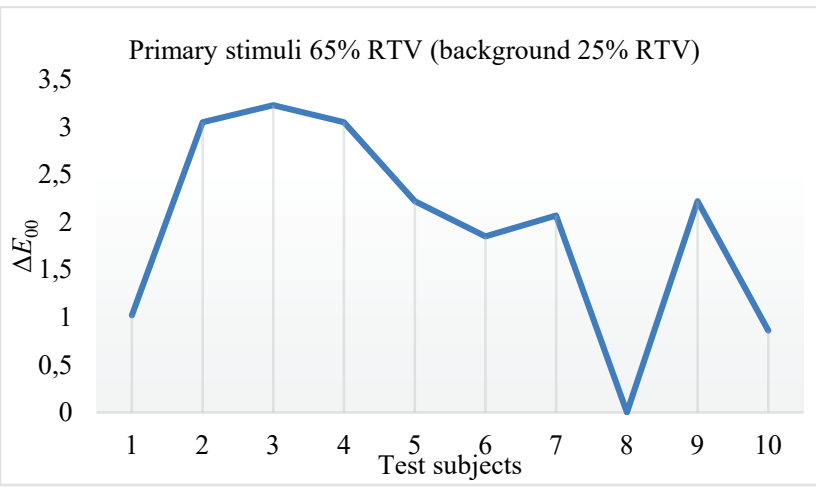

Figure 11 Display of the $\Delta E_{00}$ difference for every subject for the primary stimuli of $65 \%$ RTV on the secondary stimuli of $25 \%$ RTV

Fig. 11 presents the results of the harmonization of the primary stimuli of $65 \%$ RTV on the background of $25 \%$ $\mathrm{RTV}$, and it shows that the biggest difference belonged to subject 3, while the smallest difference belonged to subject 8 , who harmonized the test primary stimuli equivalently to the values of the original primary stimuli.

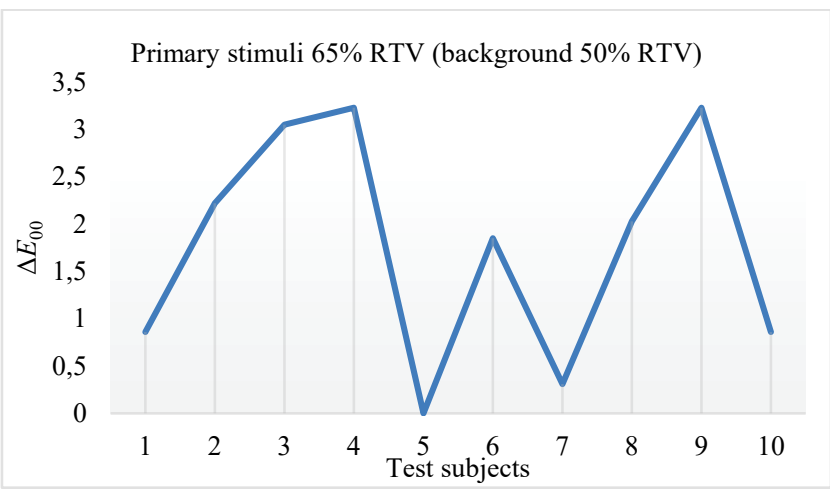

Figure 12 Display of the $\Delta E_{00}$ difference for every subject for the primary stimuli of $65 \%$ RTV on the secondary stimuli of $50 \%$ RTV 
In Fig. 12, where it can be seen that the subjects had the task to harmonize the primary stimuli of $65 \%$ RTV on the background of $50 \% \mathrm{RTV}$, it is shown that the biggest difference belonged to subjects 4 and 9 , while on the other hand, the smallest difference belonged to subject 5 , due to the fact that subject 5 harmonized the values of the test stimuli equivalently to the referential stimuli.

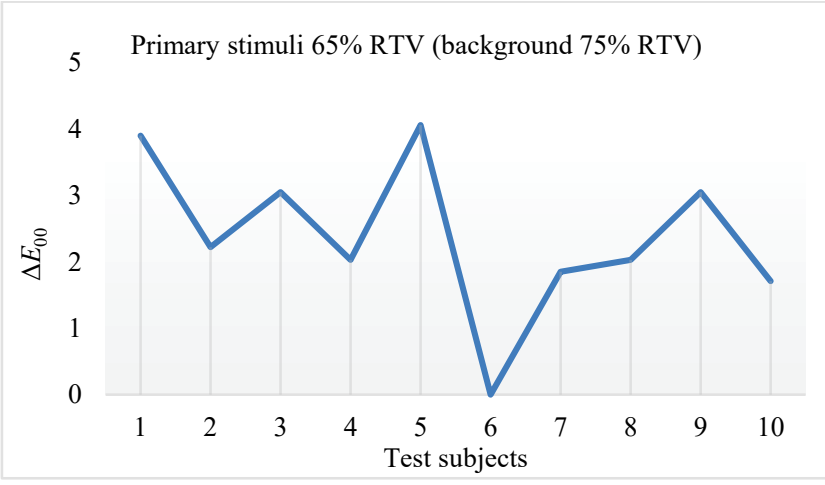

Figure 13 Display of the $\Delta$ E00 difference for every subject for the primary stimuli of $65 \%$ RTV on the secondary stimuli of $75 \%$ RTV

In Fig. 13, where it can be seen that the subjects had the task to harmonize the primary stimuli of $65 \%$ RTV with the background of $75 \% \mathrm{RTV}$, it is shown that the biggest difference belonged to subject 5 , and that the smallest difference belonged to subject 6 , who harmonized the test stimuli equivalently to the original stimuli (referential).

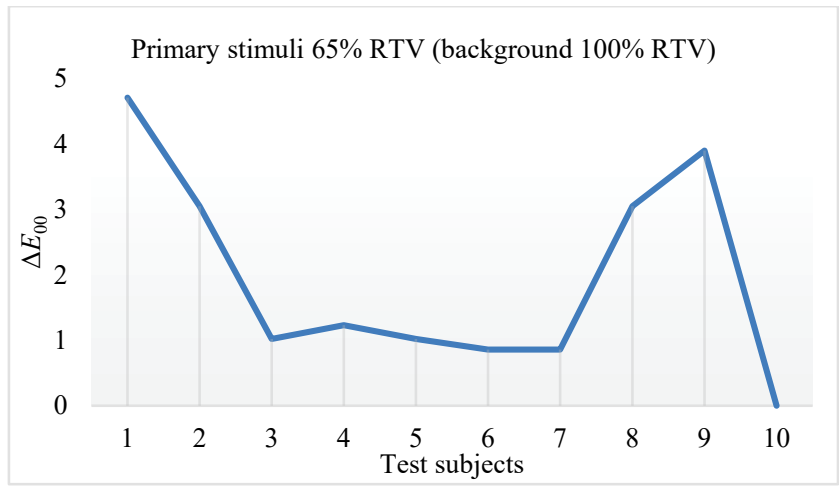

Figure 14 Display of the $\Delta$ E00 difference for every subject for the primary stimuli of $65 \%$ RTV on the secondary stimuli of $100 \%$ RTV

In Fig. 14, where it can be seen that the subjects had the task to harmonize the primary stimuli of $65 \%$ RTV with the background of $100 \%$ RTV, it can be seen that the biggest difference belonged to subject 1 , and that the smallest difference belonged to subject 10 on the primary stimuli, where there was actually no difference.

In the Figs. 15-18, it can be seen how big the difference of every subject is for both primary stimuli (55\% RTV and $65 \%$ RTV) on every background variation.

Fig. 15 shows the comparison of both test primary stimuli for every subject on the secondary stimuli of $25 \%$ RTV. From Fig. 15 it can be seen that the subjects accomplished nearly identical results of the harmonization on both primary stimuli. In other words, the overall sum of the $\Delta E_{00}$ values for the test primary stimuli of $55 \% \mathrm{RTV}$ is 21,74 , and the overall sum of the $\Delta E_{00}$ values for the test primary stimuli of $65 \% \mathrm{RTV}$ is 19,55 .

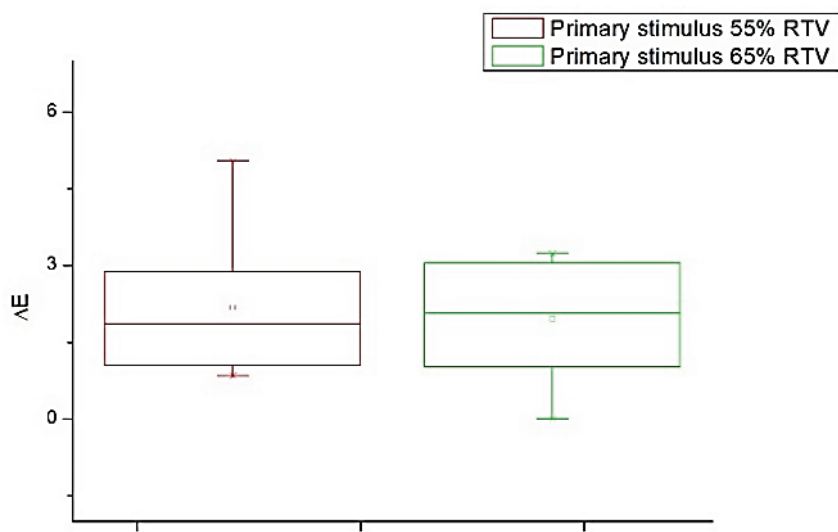

Figure 15 Presentation of the values obtained for all subjects for both primary stimuli on the secondary stimuli of $25 \%$ RTV

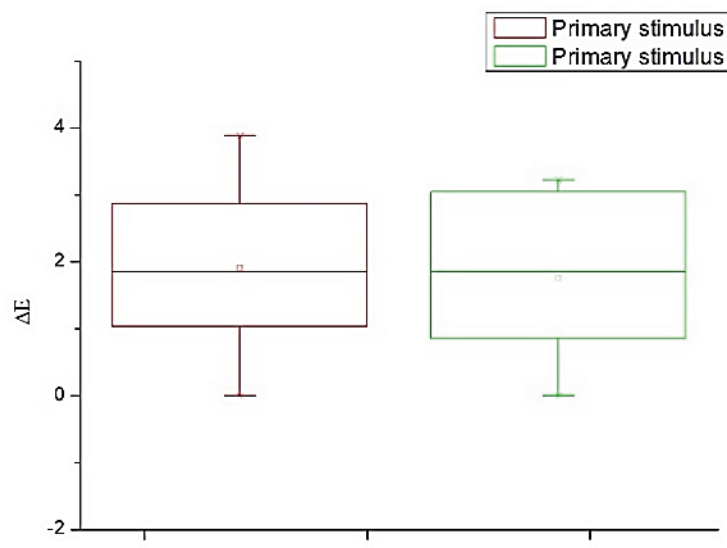

Figure 16 Presentation of the values obtained for all subjects for both primary stimuli on the secondary stimuli of $50 \%$ RTV

In Fig. 16, a comparison of both primary stimuli on the background of $50 \%$ RTV for all subjects can be seen. From Fig. 16 it can be concluded that the subjects had nearly identical results in the harmonization of both primary stimuli, as it was the case with the preceding primary stimuli of $25 \%$ RTV (Fig. 15). In fact, the overall sum of the $\Delta E_{00}$ value for the primary stimuli of $55 \%$ RTV is 19,13 , while the overall sum of the $\Delta E_{00}$ value for the primary stimuli of $65 \%$ RTV is 17,62 .

Fig. 17 shows the comparison of both test primary stimuli with the secondary stimuli of $75 \%$ RTV for all subjects. From Fig. 17 it can be seen that the subjects had considerably enhanced results in the harmonization of the primary stimuli of 55\% RTV with regard to the primary stimuli of $65 \%$ RTV, where the difference has lower oscillations, but they are significantly more pronounced with regard to the referential primary stimuli. The overall sum of the $\Delta E_{00}$ value for the test primary stimuli of $55 \%$ RTV is 16,94 , and the overall sum of the values $\Delta E_{00}$ for the test primary stimuli of $65 \%$ RTV is 23,89 . 


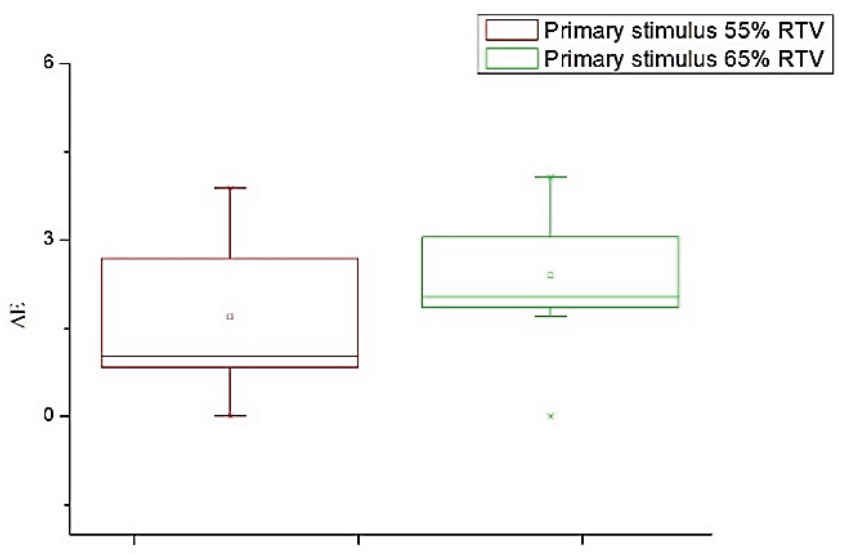

Figure 17 Presentation of the values obtained for all subjects for both primary stimuli on the secondary stimuli of $75 \%$ RTV

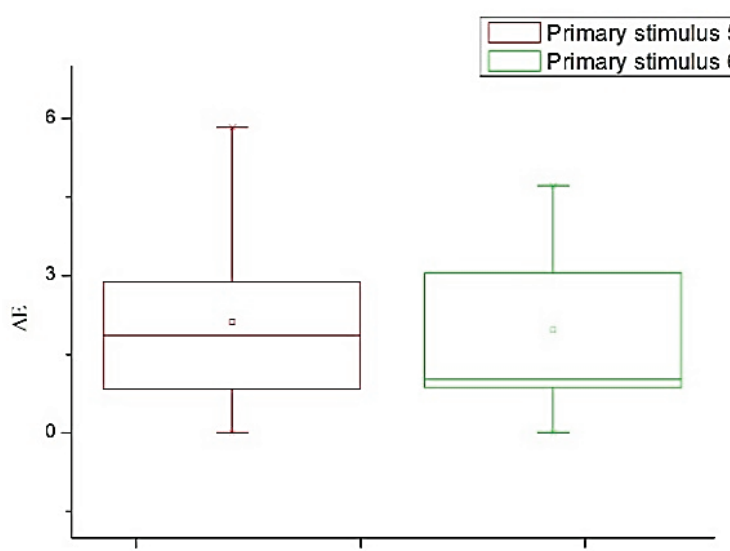

Figure 18 Presentation of the values obtained for all subjects for both primary stimuli on the secondary stimuli of $100 \%$ RTV

In Fig. 18 a comparison of both test primary stimuli for all subjects on the background of $100 \%$ RTV can be seen. Namely, Fig. 18 shows that subjects had fewer difficulties in the harmonization of the primary stimuli of $65 \%$ RTV with regard to the primary stimuli of 55\% RTV. Moreover, the conclusion is that when harmonizing the test primary stimuli of $65 \%$ RTV, the subjects had less problems in coming close to the values of the referential primary stimuli. The overall sum of the $\Delta E_{00}$ value for the test primary stimuli of $55 \%$ RTV is 21,11 , and the overall sum of the value $\Delta E_{00}$ for the test primary stimuli of $65 \% \mathrm{RTV}$ is 19,69 .

\section{CONCLUSION}

Designers, while working on their conceptual solution, unintentionally resort to the use of certain color pairs and geometric shapes that lead to the unwanted manifestation of background effects. This research created a design solution with a combination of complementary color pairs, a combination in which the primary stimuli was made in the purple color, while the background was made in the greenblue color, which led to the manifestation of the effect of crispening. With the manifestation of the effect of crispening, most subjects found it difficult to harmonize the colors of the test primary stimuli with the colors of the referential primary stimuli. That problem appeared precisely due to the variation in the background color.

Taking into account the results of every subject, there is a small difference between the original and reproduction stimuli on the samples when we compare both primary stimuli on all variations of the secondary stimuli. Namely, the overall sum of the $\Delta E_{00}$ values of the test primary stimuli of $55 \% \mathrm{RTV}$ is 78.92 , and the overall sum of the $\Delta E_{00}$ values of the test primary stimuli of $65 \%$ RTV is 80.75 . Observing the value of the test primary stimuli for each variation of the background individually, the smallest difference was recorded with the primary stimuli of $55 \% \mathrm{RTV}$ on the secondary stimuli of 75\% RTV, and the biggest difference was recorded with the primary stimuli of $65 \%$ RTV on the background with the same value as that of the test primary stimuli of 55\% RTV. The best way to avoid the problem that occurs in this research is not to use geometrical shape and color combination like this one. If it necessary to use a color combination and geometrical shape that was used in this paper, the designers should consider using the color ratio that showed the smallest deviations in perception during the appearance of crispening effect like it was the case in this research paper.

\section{REFERENCES}

[1] Chevreul, M. E. (1967). The principles of harmony and contrast of colors and their applications to the arts. New York / Reinhold Publishing Corporation, (Original work published 1839).

[2] Helmholtz, v. H. (1962). Treatise on physiological optics (Vol. 2) (Southall, J. P. L. Trans.). New York / Dover, (Original work published 1866).

[3] Kingdom, F. (1997). Simultaneous contrast: The legacies of Hering and Helmholtz. Perception, 26(6), 673-677. https://doi.org/10.1068/p260673

[4] Wade, N. J. (1996). Descriptions of visual phenomena from Aristotle to Wheatstone. Perception, 25(1), 1137-1175. https://doi.org/10.1068/p251137

[5] Whittle, P. (2003). Contrast colours, In R. Mausfeld, R. \& Heyer, D. (Eds.), Colour Perception: Mind and the physical world. Oxford University Press, 115-138.

[6] Hering, E. (1964). Outline of a theory of light sense (Hurvich, L. M \& Jameson, D. Trans.). Cambridge / Harvard University Press, (Original work published 1905)

[7] Cornsweet, T. (1970). Visual perception, Academic Press Inc., New York.

[8] Helmholtz, v. H. (1867). Handbuch der Physiologischen Optik. Leipzig / Voss.

[9] Beck, J. (1972). Surface Color Perception. Ithaca, Cornell University Press, New York.

[10] Wyszecki, G. (1986). Color appearance, In Boff, K., Boff, R., Kaufman, L., \& Thomas. P. J. (Eds.), Handbook of Perception and Human Performance (Vol. 1: Sensory Processes and Perception), John Wiley \& Sons, New York.

[11] Shepherd, A. J. (1999). Remodelling colour contrast: implications for visual processing and colour representation. Vision Research, 39(7), 1329-1345. https://doi.org/10.1016/S0042-6989(98)00232-6

[12] Ichihara, S., Kitagawa, N., \& Akutsu, H. (2007). Contrast and depth perception: effects of texture contrast and area contrast. Perception, 36(5), 686-695. https://doi.org/10.1068/p5696 
[13] Fairchild, M. D. Color Appearance Models, Second Edition, John Wiley \& Sons Ltd, England, 2005

[14] Takasaki, H. (1966). Lightness change of gray induced by change in reflectance of gray background. Journal of the Optical Society of America, 56(4), 504-509. https://doi.org/10.1364/JOSA.56.000504

[15] Takasaki, H. (1967). Chromatic Changes Induced by Changes in Chromaticity of Background of Constant Lightness. Journal of the Optical Society of America, 57(1), 93-96. https://doi.org/10.1364/JOSA.57.000093

[16] Semmelroth, C. C. (1970). Prediction of Lightness and Brightness on Different Backgrounds. Journal of the Optical Society of America, 60(12), 1685-1689. https://doi.org/10.1364/JOSA.60.001685

[17] Whittle, P. (1992). Brightness, discriminability and the "Crispening Effect". Vision Research, 32(8), 1493-1507. https://doi.org/10.1016/0042-6989(92)90205-W

[18] Hajdek, K., Budimir, I., \& Mrvac, N. (2017). The intensity of the background visual effect of crispening depending on background lightness. Tehnički vjesnik, 24(5), 1571-1578. https://doi.org/10.17559/TV-20160504125704

[19] Hajdek, K., Budimir, I., \& Krizmanić, K. (2016). The appearance of the visual effect simultaneous contrast depending on the printing substrate. Acta graphica, 27(3), 714.

[20] Hajdek, K., Budimir, I., \& Vusić, D. (2016). The intensity of the simultaneous contrast effect depending on the change of background lightness. Tehnički vjesnik, 23(2), 525-531. https://doi.org/10.17559/TV-20160122205606

[21] Xin, J. H., Lam, C. C., \& Luo. M. R. (2004). Evaluation of the crispening effect using CRT-displayed colour samples. Color research and application, 29(5), 374-380. https://doi.org/10.1002/col.20045

[22] Ho, K. M. R., Cui, G., Luo, M. R., \& Rigg, B. (2002). A Lightness Difference Formula for Predicting Crispening Effects. The $10^{\text {th }}$ Color and Imaging Conference, Scottsdale, Arizona, USA, 161-165.

[23] Bradić, P., Hajdek, K., Matijević, M., \& Hajdek, M. (2017). The influence of the chromatic effect of crispening on the shift in the manifestation of the color of the observer. Acta graphica, 28(3), 85-92.

[24] Milković, M., Mrvac, N., \& Vusić, D. (2009). Vizualna psihofizika $i$ dizajn. Veleučilište u Varaždinu, Varaždin, Croatia.

[25] Lukaček, M., Milković, M., \& Hajdek, K. (2013). Analiza manifestacije McCollough efekta u Cross-Media reprodukcijskim sustavima. Tehnički glasnik, 7(2), 170-176

[26] Kuehni, R. G. (2003). Color Space and Its Divisions, John Wiley \& Sons, New Yersey.
Authors' contacts:

Krunoslav HAJDEK, PhD, Assistant Professor

University North

104. brigade 3

42000 Varaždin, Croatia

E-mail: khajdek@unin.hr

Petra BRADIĆ

University North

104. brigade 3

42000 Varaždin, Croatia

E-mail: pbradic@unin.hr

Martina HAJDEK

Faculty of Graphic Arts

Getaldićeva ulica 2

10000 Zagreb, Croatia

E-mail: martina.hajdek@grf.com

Mile MATIJEVIĆ, PhD, Assistant Professor

Faculty of Graphic Arts

Getaldićeva ulica 2

10000 Zagreb, Croatia

E-mail: milematijevich@gmail.com 